\title{
Intelligent Transportation System (ITS) - A Review
}

\author{
Rinkal Dudhwala ${ }^{1}$, Dr. J. R. Pitroda ${ }^{2 *}$ \\ ${ }^{1} P G$ Scholar, Transportation Engineering, Civil Engineering Department, BVM engineering College, \\ Vallabh Vidyanagar, Gujarat. \\ ${ }^{2}$ Associate Professor, PG Coordinator Construction Engineering and Management, Civil Engineering \\ Department, BVM Engineering College Vallabh Vidyanagar, Gujarat
}

*Corresponding Author: Dr. J. R. Pitroda, Associate Professor, PG Coordinator Construction Engineering and Management, Civil Engineering Department, BVM Engineering College Vallabh Vidyanagar, Gujarat

\begin{abstract}
India, the second most populated nation after China is accomplishing its statures with respect to transportation building. With the expansion in populace, relocation from provincial to urban and unexpected solid financial ascent has unambiguously squeezed the essential offices, administrations and establishments required for the working of transportation framework. In addition, there will be increment in the quantity of vehicles. Shoot up in the quantity of vehicles, traffic issues consistently exist. The transportation offices like current unmanaged transient sign need framework make it hard to control the movement time, crashes at convergences and productive timetable adherence. Wastefulness in vehicle leaving makes it hard to alter and mastermind the expanding number of vehicles in an appropriate, satisfactory and helpful way. Erroneous administration in the situation of drivers, following the clogged course in any event, when there are backup ways to go focuses on vehicle sticking and time travel increase. So, it is important to have an administration framework which should handle all the above issues in a productive way. This examination is planned for checking on an Intelligent Transportation System (ITS) and advances related with transportation framework. Executing this framework reserves accessible parking spot to a driver to leave their vehicle and recharges the accessibility of parking spot when vehicle leaves. It will prompt the holes in the information which can be additionally contemplated. The paper features the ends separated from the investigations of various frameworks and furthermore gives the future degree in the field of ITS to make it easier to understand and available.
\end{abstract}

Keywords: Intelligent Transportation; System; Advanced Traveler; Information System; Advanced Traffic; Management System; Advanced Public; Transportation System

\section{INTRODUCTION}

In the current paper various ITS engineering and model created by different specialists everywhere throughout the world has been considered and checked on to get top to bottom of their design. In the examination the ITS has been sub-separated in four primary branches based of their usage in various parts of transportation the executives for example ATIS, APTMS, ATMS and EMC. A correlation investigation of the various models created in every one of the four branches have been done to feature the in addition to and less purposes of these created frameworks and dependent on that the holes in the writing have been featured.

Keen Transport System is a vehicle framework which makes a vehicle or vehicles to work easily during its excursion time and gives wellbeing and solace to an individual vehicle or a system of vehicles utilizing the propelled procedures like Global Positioning System (GPS) and Global Navigation Satellite System (GNSS), Cooperative Intelligent Transport System (C-ITS). Insightful Transport System can be applied for each method of transportation viz. streets, railroads, water or air. The administrations that are given by Intelligent Transport System to the two travelers and payloads are of most extreme significance. Web alongside sensors and satellites has been progressively assuming a significant job in transportation framework. GPS, GNSS and CCTV cameras, street side variable message signs helps in assurance against the dangers in the vehicle framework, decreases breaks in rush hour gridlock, improves travel time and viably diminishes the pace of mishaps. For over decades, the information on traffic designing has been given to support the drivers/travelers to settle on entrenched 
and advance choices. In later years, the development of Intelligent Transportation Systems (ITS) and Advanced Traffic Management Systems (ATMS) have begun to improve transportation by methods for web innovation. Similarly, Intelligent Vehicle Highway Systems (IVHS), frameworks that "obtain, resolve, send, and depict data to help transportation travelers in moving from a beginning spot to their ideal foreordained end" would now be able to be utilized for in transit help alongside the assortment of traffic information. In the end, innovation is instating to recognize the significance of engendering of post-trip data by outfitting data on the accessibility and area of stopping. Significant territories of ITS are web sites, checking of streets, following of individual vehicles, observing and the executives of transport process. This paper audits the innovations that are utilized in ITS. The figure 1 shows Intelligent Transportation System.

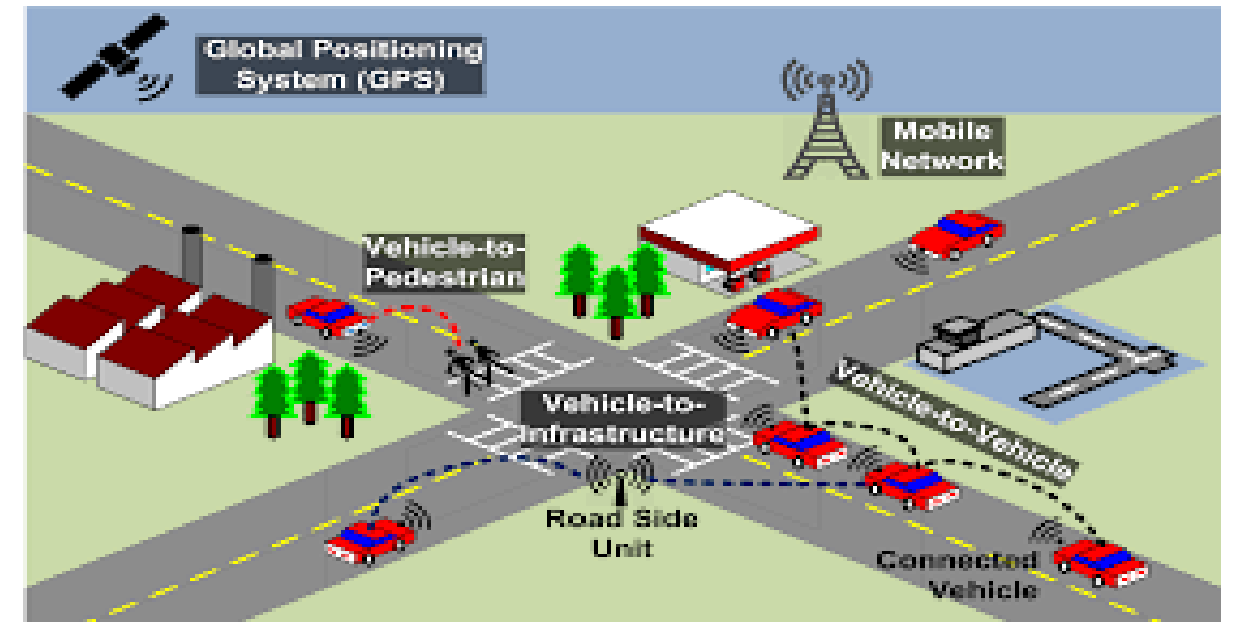

Figure1. Intelligent Transportation System

ITS is an incorporated framework that actualizes a wide scope of correspondence, control, vehicle detecting and gadgets advancements to help in checking and overseeing traffic stream, diminishing blockage, giving ideal courses to voyagers, upgrading profitability of the framework, and sparing lives, time and cash. A Technical Note of the World Bank named "ITS for Developing Countries" addresses the state of ITS in creating nations, and talks about the long haul, society-wide advantages that ITS can give and ways that ITS can give more quick advantages to people by assisting with making surface transportation more moderate, more solid, and more effective. It expresses that ITS ends up being helpful in the accompanying way: Improved mobility for people and freight, including greater access to transportation for the elderly, the disabled, and people living in remote locations

- Greater compatibility of surface transportation with the environment

- Fewer traffic-related deaths and injuries

- A better-managed transportation system.

- Less travel uncertainty, allowing for better planned, quicker, and less expensive travel

- So, from the above points we can see that ITS covers and improves almost all the aspects of Transportation engineering. There are many subsidiaries of the Intelligent Transportation System out of which most important and widely used all over the world to solve the traffic and transportation problem are as follows:

- Advanced Traveler Information System (ATIS)

- Advanced Traffic Management System (ATMS)

- Advanced Public Transportation System (APTS)

- Emergency Management System (EMS)

Propelled Traveler Information System (ATIS) executes a wide scope of advances, for example, web, phones, PDAs, TV, radio, and so on to help voyagers and drivers in settling on educated choices with respect to trip takeoffs, ideal courses, and accessible methods of movement. ATIS gives the drivers both on the way and pre-trip data which is favorable from numerous points of view. Pre-trip data accessibility improves the self-conviction of the drivers to utilize turnpikes and permits workers to settle on better- 
educated travel decisions. On the way data and direction spares travel time, enables a voyager to dodge clog, can improve traffic arrange execution. In 1999 an overview was directed among the individuals who were utilizing the Advanced Regional Traffic Interactive Management and Information System (ARTIMIS) phone voyager data administration in Cincinnati, Ohio. Every one of them appraised the administration as useful assistance. Over $99 \%$ of individuals overviewed in that city said that they were profited by maintaining a strategic distance from traffic issues, sparing time, diminishing disappointment, and showing up at goals on schedule and $81 \%$ said that they had prescribed the administration to another person.

\section{RECENT TECHNOLOGIES IN INTELLIGENT TRANSPORT SYSTEM}

The following are recent technologies in intelligent transport system

\subsection{Co-Operative Risk Warning Systems}

This framework means to lessen gridlock, brings down the pace of mishaps and furthermore brings down the pace of carbon dioxide discharge. For the clogged zones because of gridlocks, outflow of carbon dioxide will be more and the specific region where the blockage happens will get influenced. Thus, by the utilization of co-usable hazard cautioning framework (C-ITS) board gear, the vehicles which are interconnected, will move their data to the slacking vehicle by which the later will follow another course to evade gridlocks. The figure 2 shows Co-operative Risk Warning Systems.

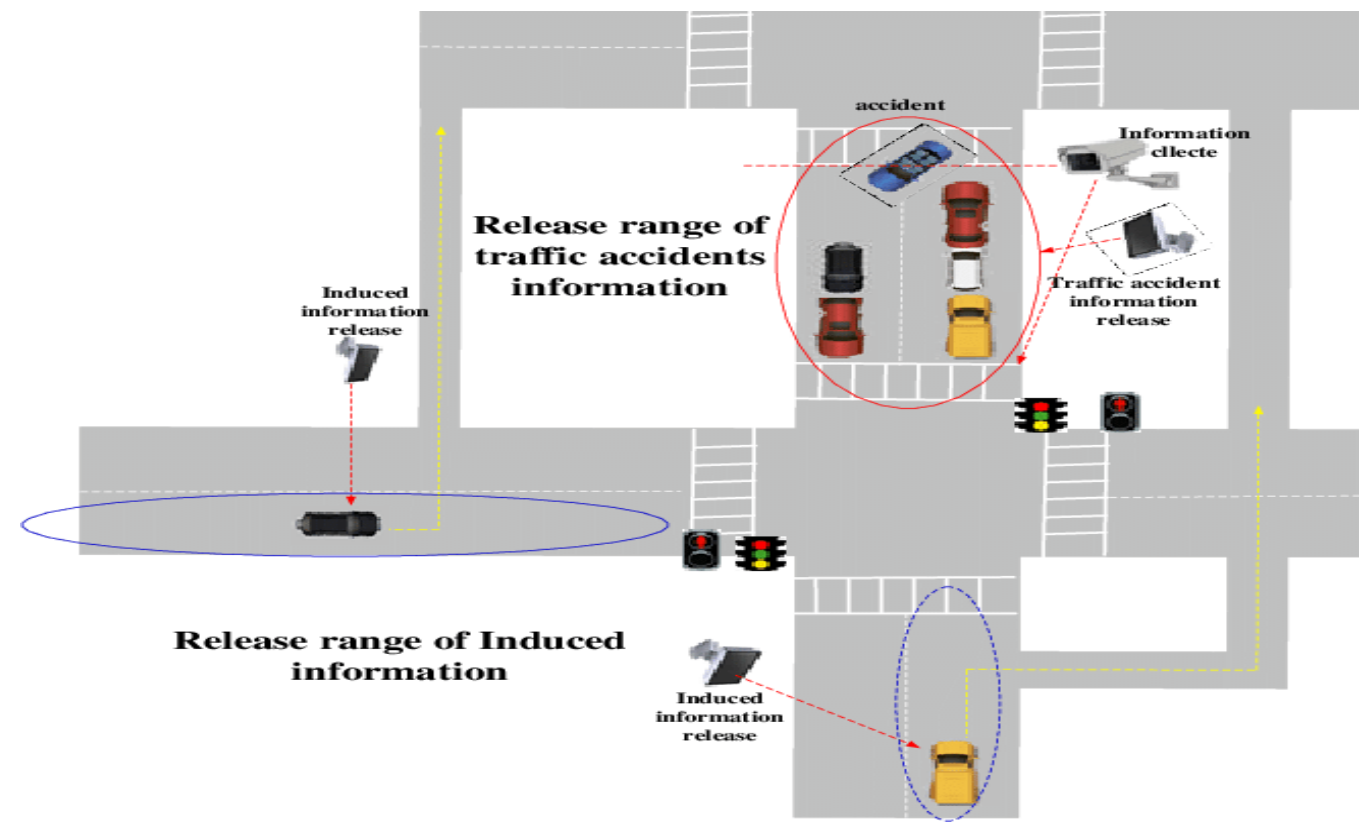

Figure2. Co-operative Risk Warning Systems

\subsection{Highway Data Collection (HDC)}

HDC innovation ensures promotion of traffic information in ITS. This innovation depends on the uses of GPS, GNSS, GSM and GPRS that work with the assistance of sensors inserted in the vehicles and give base information to the traffic light community for retribution, looking at, settling and building up traffic stuffing, travel time [1]. In addition, it gathers the breeze speed, climate information and territory information.

\subsection{Electronic Toll Collection (ETC)}

Electronic Toll Collection revokes deferment in rush hour gridlock and includes the highlights in the component of gathering cost consequently and electronically in transportation division. and so, on idea shoots up the execution of extracts, wellbeing season of voyagers and furthermore helps in beating a few issues relating to the earth and utilization of fuel. And so forth, really goes through Dedicated ShortRange Communication [1]. In this framework, a gadget known as On-Board Unit (OBU) is introduced in the vehicle and another gadget known as Road Side Unit (RSU) is introduced Out and about in the cost station. Both these units convey each other inside the scope of 30 meters. Immediately over 10 seconds, the cost is gathered from the vehicle proprietor consequently by the cooperation of OBU and RSU. By introducing such framework, it has been discovered that the congestion at cost stations has 
been brought down by 40\%. Thusly it expands the exhibition of cost stations and diminishes the deferrals in rush hour gridlock framework. The figure 3 shows Electronic Toll Collection (ETC).

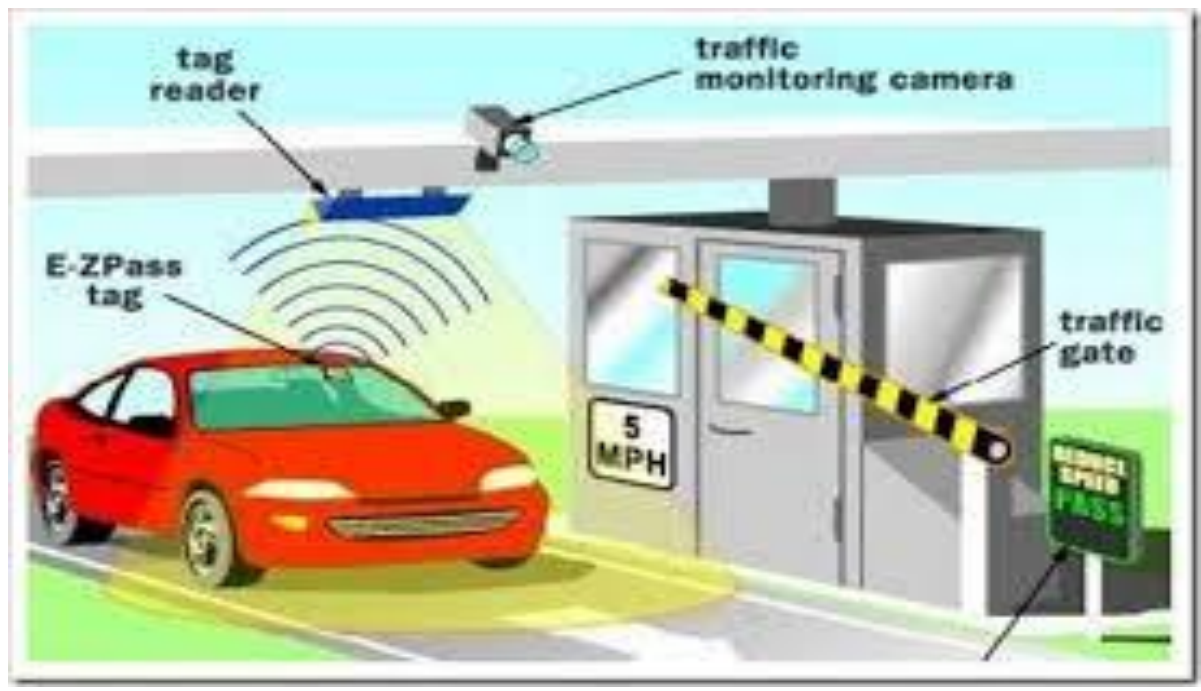

Figure3. Electronic Toll Collection (ETC)

\subsection{Sensing Technology in ITS}

Detecting innovation in transportation framework has been never observed. This innovation runs by the length required by a PC framework to finish a specific errand, along these lines start to finish postponement and synchronicity is significant for such frameworks. The figure 4 shows Sensing Technology in ITS.

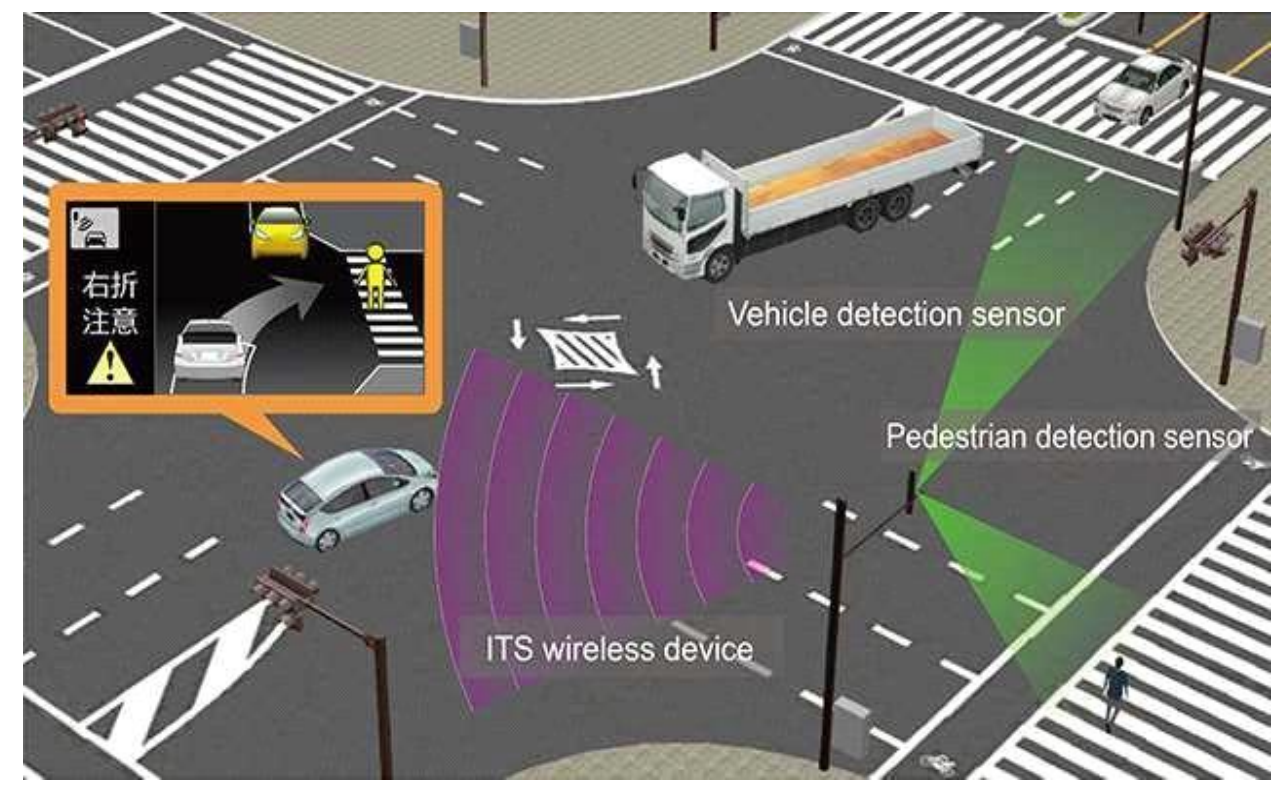

Figure4. Sensing Technology in ITS

In remote sensor organize (WSN) the sensors or hubs are introduced for information assortment through various long-range associations like satellite, Wi-Fi, WIMAX, and so forth. Sensor organize exist in various sorts, for example, warm for assortment of temperature information, acoustic for clamor assortment, infra-red for moistness information assortment and so forth. These sensors have adequate ability to manage or follow different conditions in particular temperature reconnaissance, suddenness noticeable all around, vehicle movement, pressure, commotion, speed, and course and so on. Force unit, Transceiver, sensing unit and Processing unit are the four segments of sensor hub. An extra unit is utilized for attaching the area.

\subsubsection{Advanced Traveler Information System (ATIS)}

ATIS is a zone of exploration since past 2-3 decades around the world. In the 1990's the greater part of the work in this field is predominantly done in the U.S.A. what's more, European nations. Be that as it 
may, since the 21st century, work has been begun in the Asian and African districts too. In this area of the writing audit contemplates directed in India and studies completed outside India has been checked on and contrasted with give favorable circumstances and drawbacks of the frameworks: introduced a technique for planning a Geographic Information Systems (GIS) based Automatic Transit Traveler Information System (ATTIS). The thought behind the investigation was to furnish the clients ideal excursion choice with least travel time between the explorer's inception and goal, including strolling, pausing, move, and in-vehicle time. To accomplish the reason for giving the ideal course the procedure which was embraced is to consider just those bus station focuses which are dynamic (have administration) at the hour of movement as all the bus station focuses don't have the administration all $24 \times 7$ and considering just dynamic bus station point brings about ideal course.

\subsubsection{Advanced Traffic Management System (ATMS)}

ATMS is one of the most unmistakable and utilized part of ITS. This segment of the writing survey incorporates the various investigations which have been made in the field of ATMS to give the similar conversation of the examinations:

Logi and Ritchie (2001) depicted an ongoing Knowledge Based System (KBS) for choice help in the determination of coordinated traffic signal plans after the event of non-repeating blockage. In this examination, two calculations were created for example information combination calculation for the examination of clog and a calculation for the choice of control plans. The approval results demonstrated that by the utilization of Traffic Congestion Management (TCM) travel time decreased somewhere in the range of $1.9 \%$ and $29.0 \%$ and normal stop speed diminished somewhere in the range of $14.8 \%$ and $55.9 \%$.

Faghri and Hamad (2002) contemplated the utilization of GPS in rush hour gridlock the executives. In their examination use of GPS was associated with gathering traffic information, for example, travel time, speed and deferral on 64 significant streets in the territory of Delaware. At the point when mean and change of the outcomes acquired by both the techniques were looked at and no critical distinction was watched. GPS information was seen as half more effective as far as labor.

Hernandez et al. (2002) joined the utilization of man-made reasoning strategies in rush hour gridlock the board and gave a multivalent design for shrewd traffic the executive's frameworks. Two multispecialist information-based frameworks, InTRYS and TRYSA2 were created to perform choice help for ongoing traffic the executives. The exhibition of both the frameworks was assessed and general appropriateness of multi-specialist models for keen traffic the executives was given.

\subsubsection{Advanced Public Transport Management System (APTMS)}

Present segment comprises of the basic survey of the examinations that have been made in the field of APTMS to give basic investigation of various frameworks:

Molina (2005) portrayed the design of a PC framework that followed the possibility of an information based clever right hand for open vehicle the executives. The given design fills three needs for example analysis, forecast and arranging. The model depicted, was applied for the improvement of two distinctive genuine applications for the urban communities of Torino (Italy) and Vitoria (Spain).

Feizhou et al. (2008) utilized Genetic Algorithm (GA) and Hybrid Genetic Algorithm (HGA) for ideal planning of open vehicles dependent on the genuine operational conditions. The presentation for three sorts of vehicular levels (for example least, normal and most extreme) was looked at utilizing one-point and two-point hybrid tasks. Transport highway 375 in Beijing was taken by the scientists for instance and the framework was applied. The outcomes indicated that it served to sensibly assign open vehicle assets and improved effectiveness.

\subsubsection{Emergency Management System (EMS)}

Because of its tendency and commitment in setting aside lives and cash a great deal of work is occurring in the field of EMS. This area talks about the various EMS built up everywhere throughout the world to give basic audit:

Thapar (2001) introduced a GIS based crisis reaction the executive's framework for Hyderabad city which can give the valuable data with respect to various offices and ideal courses during crisis circumstances. In this investigation the likely hazard zones were resolved dependent on the land use, 
building exercises according to National Building Code (NBC) rules. Productivity and viability of the fire administration was considered and dependent on this an Emergency Response Management System was created.

\section{CONCLUSION}

From the above conversation obviously the vast majority of the ITS investigations have been situated in the created nations. In creating nations still, a lot of work is required in this field to take care of the rising traffic related issues. The vast majority of the ITS frameworks have been created on the GIS or WWW stages. Both the stages have their own preferences. While GIS stage gives exceptionally incredible spatial examination strategies though WWW stage end up being extremely valuable in giving constant data. Some created frameworks utilized reconciliation of the two GIS just as WWW stages which makes it conceivable to utilize the benefits of both the stages. A large portion of the created frameworks are situated in the urban territories. There is an incredible breadth of work to be done in rustic zones. The GPS is helpful in all the ITS frameworks. GPS information is half more proficient as far as labor. It was found in the writing that with the utilization of ATMS innovation the movement time was diminished around 1.9\% - 29.0\% and normal stop speed decreased around 14.8\% - 55.9\%. With the utilization of EMS, the reacting speed applied to framework is expanded around half and the all-out time expected to deal with the crisis occasion was diminished around $40 \%$ than the other conventional strategy.

In the improvement of ITS, combination of the various methods of transportation is extremely essential. Subsequently, the work ought to be done in this field. In ITS continuous data is a significant factor. GPS is one innovation which can help toward this path so the work should have been done towards making GPS more precise and efficient. In all the creating nations blended traffic conditions wins, so in the advancement of the ITS blended traffic conditions ought to likewise be considered so as to make it material in creating nations moreover. In usage of the ITS particularly in creating nations its establishment and working expense are huge elements. Consequently, the work ought to be done toward the path to make the ITS more efficient. The scope of ITS till now is constrained to barely any people so the work ought to be done so as to make it more open and easier to use. The utilization of cell phones can be extremely useful toward this path as cell phones are most ordinarily utilized electronic device everywhere throughout the world.

\section{REFERENCES}

[1] CVIS: 2010. Available at www.cvisproject.org, accessed August 2014

[2] SAFESPOT: 2010. Available at http://www.safespot-eu.org/, accessed August 2014

[3] ISO 21217:2014: 'Intelligent transport systems - communications access for land mobiles (CALM) architecture', 2014

[4] COMeSafety: 2009. Available at www.comesafety.org, accessed August 2014

[5] COOPERS: 2010. Available at http://www.coopers-ip.eu/index.php?id=project, accessed August 2014

[6] Kroh, R., Kung, A., Kargl, F.: 'SEVECOM D1.1 VANETS security requirements final version', 2006

[7] Ernst, T.: 'GeoNet D1.2 final GeoNet architecture design', 2010

[8] FOT-Net Consortium: 'FESTA handbook version 5', 2011

[9] EuroFOT: 2012. Available at www.eurofot-ip.eu, accessed December 2014

[10] TeleFOT: 2012. Available at http://www.telefot.eu/, accessed September 2013

[11] DriveC2X: 2014. Available at http://www.drive-c2x.eu/project, accessed August 2014

[12] FOTsis: 2013. Available at www.fotsis.com, accessed March 2014

[13] FOT-Net Data. Available at www.fot-net.eu, accessed December 2014

[14] Future Internet PPP Home: 2013. Available at http://www.fi-ppp.eu/,

[15] Accessed April 2014 the INFINITY Project: 2013. Available at http://www.fi-infinity.eu/portal, accessed April 2014

Citation: Rinkal Dudhwala, Dr. J. R. Pitroda, "Intelligent Transportation System (ITS) - A Review", International Journal of Constructive Research in Civil Engineering, 6(3), pp. 29-34 DOI: https:// doi.org/10.20431/2454-8693.0603004.

Copyright: () 2020 Authors, this is an open-access article distributed under the terms of the Creative Commons Attribution License, which permits unrestricted use, distribution, and reproduction in any medium, provided the original author and source are credited. 